\title{
Heterogeneidad textual y neovanguardia: los poemas acéntricos y quipullagemas de José Luis Ayala
}

\author{
Giovanna Iubini Vidal \\ Instituto CREAR, Universidad San Sebastián, Chile \\ giovanna.iubini@uss.cl
}

\section{Resumen}

Analiza las propuestas textuales en la obra del poeta puneño José Luis Ayala, especialmente, los poemas acéntricos y quipullagemas de Cábala para Inmigrantes ( $A n$ tilaveno/ Poemallages). Propone que estos experimentos textuales constituyen una forma de heterogeneidad textual, una escritura fronteriza que desafía sistemas epistemológicos, culturales y literarios, cuya finalidad es la ampliación de la noción de literatura. Su especial condición neovanguardista deviene de la vinculación entre la estética de la vanguardia andina, principalmente de Oquendo de Amat y matrices culturales andinas como el quipu.

Palabras clave: Heterogeneidad textual, Quipullagema, Neovanguardia, Poesía andina, José Luis Ayala

\section{Abstract}

It analyses the textual proposals in the work of the poet Puno José Luis Ayala, especially the poems Acéntricos and Quipullagemas of Kabbalah for Immigrants (Antilaveno/Poemallages). It proposes that these textual experiments constitute a form of textual heterogeneity, a frontier writing that defies epistemological, cultural and literary systems, whose purpose is the extension of the notion of literature. Its special neovanguardista condition becomes the link between the aesthetics of the Andean avant-garde, mainly of Oquendo de Amat and Andean cultural matrices like the quipu.

Keywords: Textual heterogeneity, Quipullagema, Neo, Andean poetry, José Luis Ayala 


\title{
Heterogeneidad textual y neovanguardia: los poemas acéntricos y quipullagemas de José Luis Ayala'
}

\author{
La poesía es un pan cotidiano \\ un oficio de orfebre alucinado [...] \\ Dejen que irrumpa la nueva estética \\ escrita con grafías en movimiento \\ Condición de ruptura, José Luis Ayala
}

\section{Introducción}

El amplio y dinámico proyecto literario de José Luis Ayala (Huancané, 1942), 1lama la atención tanto por su amplitud, ${ }^{2}$ como por la voluntad experimental que cruza su proyecto estético-literario. Lo primero nos hace pensar que se trata de un cultor de la palabra que ha hecho de su oficio una forma de vida - convirtiéndose en "uno de los escritores más disciplinados y prolíficos de la literatura puneña", según Mauro Mamani (p. 121)—; lo segundo, lo ha llevado a desarrollar una escritura plurigenérica, explorando desde los géneros tradicionales (poesía y narrativa) a los géneros referenciales ${ }^{3}$ (biografías, crónicas y testimonios), así como los posibles cruces entre ambos, cuyo resultado es una escritura liminar y fronteriza, que desestabiliza los paradigmas escriturales. Se trata, entonces, de textos excéntricos, inclasificables en las estanterías de las bibliotecas, a caballo entre dos universos culturales, en los que dialogan y se confrontan dos ratios de pensamiento. ${ }^{4}$

1 Este artículo forma parte de la tesis doctoral "Vanguardia andina, migrancia y heterogeneidad textual: Hacia una poética de lo cósmico en Cábala para inmigrantes de José Luis Ayala”, la cual se encuentra adscrita al Fondecyt 1141007, "Reterritorialización en las literaturas andino-amazónicas: poéticas y enunciaciones heterogéneas en confluencia" de la Dra. Claudia Rodríguez Monarca.

2 Al momento es posible contabilizar cerca de cincuenta libros publicados, cifra que hace imposible que podamos reseñarlos en detalle.

3 Leonidas Morales desarrolla la idea de que los géneros referenciales constituyen una escritura de al lado, en tanto que su estatus teórico y literario es ambiguo e inclasificable en el contexto de los géneros tradicionales. En este sentido, propone que se trata se trata de un discurso transhistórico, pues sus propiedades textuales no son históricas, no han sido "inscritas" en el tiempo, por lo tanto, es un tipo de discurso móvil y dinámico. Además, es un discurso transgenérico, pues "profita" de otros géneros para actualizarse, como sucede, por ejemplo, en novelas, cuentos o textos poéticos de carácter autobiográfico.

4 Ejemplo de esto pueden ser obras como la cronivela Wancho Lima (1989); Aymar Marka. Nación Aymara (2009), ensayo de recopilación histórica y relatos orales; Yatiris. Adivinos andinos (2009) 
Cábala para inmigrantes (Antilaveno/Poemallages) (2003), el texto en el que nos centraremos para este estudio, es una caja de sorpresas, pues su estructura no responde a la noción tradicional de libro, ya que experimentos poéticos como los quipullagemas, los poemas acéntricos, los caligramas, los dibujos, los textos encontrados y los collages ponen en cuestión nuestra concepción de poema y texto literario como unidad lingüística y abre nuevos caminos para comprender el funcionamiento semiótico de la poesía. El texto de Ayala es literalmente una caja de sorpresa, pues viene en una caja blanca de cartón (cuyas dimensiones son $31 \times 22 \times 5$ ), que contiene dos tipos de documentos: en primer lugar, cuadernillo titulado Le Moulin Rouge. Antinovela Cábala para inmigrantes, que reúne los poemas y experimentos poéticos, firmado por su heterónimo Rafael Olazábal; y, en segundo lugar, 280 hojas sueltas, numeradas y firmadas por José Luis Ayala, que constituyen su especial “antilaveno". Por su especial característica, Mauro Mamani ha dicho que de entre sus libros es:

(...) el experimento textual más arriesgado [...] que en un intento de crear una novela total, termina rompiendo con los convencionalismos del libro como objeto establecido, empastado y con páginas fijas, hasta convertirlo en un artefacto maleable, con múltiples entradas, con finales insospechados y todo guiado por la intencionalidad del lector. (p. 121).

Las hojas sueltas, además, tienen una configuración particular. Por una parte, en el anverso de las hojas encontramos una serie de textos (poemas, prosa, narración autobiográfica, dibujos, entre otros elementos) cuyo tema es el relato de viaje del sujeto migrante protagonista de la obra, Rafael Olazábal, que transita de Huancané hacia Lima y luego a París, y que como escritor emergente busca crear la novela total; la estructura de la narración apela a la actividad cooperativa del lector empírico, invitándonos a participar añadiendo al texto nuestros comentarios, variaciones e interpretaciones. En el reverso, por otra parte, vemos fotografías de collages de corte surrealista, las cuales, no obstante, no dialogan ni establecen continuidad con la narración.

Esta obra, y gran parte de su proyecto estético, está en diálogo con las vanguardias, y desde nuestra perspectiva, pretende renovarla y continuarla desde la modernidad periférica de un migrante andino en París. Sus referentes culturales no se limitan a las vanguardias europeas, más bien a la vanguardia andina, expresada en el movimiento intelectual que en Puno lideró el grupo Orkopata, plasmada en el Boletín Titikaka (1926-1931), y en la poesía de Carlos Oquendo de Amat, la que da cuenta de una asimilación creativa, crítica y activa de los postulados vanguardistas,

guía sobre la adivinación y el chamanismo en el contexto aymara; el Diccionario de Cosmopercepción andina (2011); su recopilación bilingüe Literatura y cultura aymara (2005); en el género biográfico, Carlos Oquendo de Amat. Biografía y crítica literaria (1998) y El cholo Vallejo (1994. Estos tres últimos textos demuestran la cercanía de Ayala con la primera vanguardia, influencia que se proyecta, por ejemplo, en sus Lupigramas y solemas (1990), quizá el más "excéntricos" de sus textos, al escribir sobre discos solares movibles que, mediante la rotación, nos permiten leer siempre nuevos versos y poemas y, por supuesto, en Cábala para inmigrantes (2003). 
por lo que su surgimiento "supuso una reivindicación ideológica de lo propio" (Espezúa Salmón, p. 228). En consecuencia, estamos frente a una vanguardia intercultural, que tiene como referente simbólico la experiencia andina y toda su cultura, esa "otra" literatura, al decir de Martin Lienhard (1992), que habita en la oralidad, en los cantos, en los mitos de origen y en las cosmologías.

Otro elemento que evidencia la relación entre el proyecto de Ayala y la vanguardia andina es su participación en el grupo puneño "Promoción Intelectual Carlos Oquendo de Amat”. Este grupo que surgió a mediados de los sesenta, contaba entre sus integrantes con Ayala, Gloria Mendoza Borda, Omar Aramayo, Gonzalo García y Percy Saga. Su denominación homenajea y alude a las poéticas andinas (Mamani, 2009). El testimonio de Gloria Mendoza Borda resulta clave para comprender cómo se conjugan estos elementos en el sistema de preferencias del grupo:

En cierta medida nos acercaba un cordón umbilical a lo que fue el Grupo Orkopata [...] por ser otra época teníamos seguramente muchos de nosotros la influencia de Oquendo, de Heraud, de los surrealistas franceses, del socialismo, de los Orkopatas, sobre todo de la cultura andina aymara y quechua, con la pureza de sus colores, de las zampoñas, de la danza, de la diablada, de las islas encantadas, del lago eterno en el espejo de nuestros ojos distantes (p. 136)

En este sentido, proponemos que los quipullagemas y poemas acéntricos de José Luis Ayala constituyen una forma de heterogeneidad textual, es decir, una escritura fronteriza que conjuga sistemas epistemológicos, culturales y literarios distintos, cuya finalidad es la ampliación de la noción de literatura. Su especial condición neovanguardista deviene, tal como aquí se señala, de la vinculación entre la estética de la vanguardia andina (fundamentalmente en la obra de poetas puneños como Oquendo de Amat) y matrices de la cultura y pensamiento andino (el quipu, por ejemplo).

\section{Coordenadas teóricas: transdiscursividad, heterogeneidad textual y neo- vanguardia}

El diálogo que la obra de Ayala establece entre el sustrato cultural andino y la vanguardia, debe comprenderse como una original manera de tender puentes, vasos comunicantes, entre la literatura indígena y la occidental, en tanto que constituye un proyecto estético-literario transdicursivo. Un repertorio transdiscursivo tiene como característica que a nivel textual los poetas se permiten integrar "su tradición y memoria cultural, pero al mismo tiempo recurrir a registros de otras escrituras" (Rodríguez, 2013, p. 166), de tal modo que existe una vinculación, y a veces también un cuestionamiento y confrontación, entre lo vernáculo y lo foráneo como ejes de la escritura. Claudia Rodríguez ha identificado que los ejemplos más notables de esta actitud corresponden a: "el caso mapuche, en Jaime Huenún, Bernardo Colipán, César Millahueique, Roxana Miranda; en la poesía quechua Odi Gonzales, 
Fredy Roncalla; Efraín Miranda y José Luis Ayala en los aymaras; y los guaraníes Mariano Rubén Álvarez y Susy Delgado” (ibíd.).

En estas literaturas la articulación de lo propio se hace en relación con otras fuentes culturales y estéticas, por lo que se trata de enunciaciones heterogéneas, donde el sujeto enunciador de los textos poéticos responde a "su realidad y condición intercultural y a pesar de su competencia bilingüe y bicultural no logra integrarse, hacer síntesis, sino que opta por una de sus herencias o por evidenciar esa tensión no resuelta (Rodríguez, 2009, p. 186). De este modo, el poeta no es, necesariamente, un mediador cultural: el estar en el "entre" no soluciona el conflicto identitario, más bien permite, desde esa especial posición, la toma de consciencia del desgarro cultural.

En la obra de José Luis Ayala se puede apreciar el conflicto de un sujeto en tránsito, en el que su raigambre cultural indígena y la vertiente occidental se articulan y confrontan a partir de una particular experiencia de migración. El sujeto de la autobiografía ficticia de Cábala para inmigrantes es un hombre andino, un escritor y yatiri - al igual que el autor-, que en su experienciar París da cuenta del derrumbe espiritual de una sociedad que trata inhumanamente al migrante de países "en desarrollo", desmitificando, así, la imagen de París como el lugar soñado, centro de la bohemia cultural que, en este caso, es presentada desde el choque cultural, el desarraigo y la nostalgia.

Se trata, entonces, de un sujeto migrante que se mueve por fronteras territoriales y espacios culturales diversos (Cornejo Polar, 2011) y que, con su movimiento "pone en acción, hace evidente y aún genera heterogeneidades" (Bueno, 2004, p. 55), con la consecuencia de que las fronteras se tornen permeables producto de su influencia (Cornejo Polar, 2011). Este migrante, sin embargo, va más allá del tránsito "sierra-capital", pues corresponde a otro estadio de migración y sería, según Julio Noriega Bernuy, un "sujeto transandino" (2012) que se mueve a través de tres mundos, culturas y lenguas, con las que debe mediar a través de tratos de sobrevivencia. No obstante, el migrante pueda construir allí un lugar de cobijo que le recuerda su "ayllu", un tercer espacio al decir de Edward Soja, eso no significa, contrariamente a la tesis de Noriega Bernuy (2012), que allí se forje un encuentro (tinkuy) o equilibro (chawpi). En la narrativa del desencanto y los sueños de desarraigo de Cábala para inmigrantes lo que se evidencia es un desencuentro frente a ese mundo que lo ve como una otredad, como una amenaza, por lo que si hay "encuentro" éste no es con la imagen retiniana de la ciudad de las luces, sino que con la comunidad de migrantes que viven en las mismas condiciones, que generan una red de apoyo.

En este sentido, creemos que es imposible comprender la totalidad de esta obra si no relacionamos el fenómeno de la migración, con las nociones de transdiscursividad y enunciación heterogénea, pero estos elementos que atañen al argumento 
de la obra no explican su compleja estructuración, la voluntad experimental y la exploración multidimensional que en ella se presenta, aspectos que nosotros conceptualizamos como una forma de heterogeneidad textual.

Proponemos la heterogeneidad textual como la confluencia en un mismo texto literario de múltiples formas expresivas, géneros literarios y tipos de discursos, que diversifican la estructura textual, la hacen múltiple y compleja, motivo por el cual las obras que responden a estas características se encuentran en una cierta indeterminación genérica que torna difícil su clasificación en una tipología textual. La finalidad de este procedimiento inclusivo puede ser tanto complementar el argumento o tema de la obra, como constituir, en sí mismo, parte fundamental del motivo de la obra, de modo que la reflexión sobre ese procedimiento literario se plasmará mediante formas de autoconsciencia estética como la metatextualidad y la metaficción. Cualquiera sea el objetivo, este recurso tiene como consecuencia que se amplíe la noción de literatura y de géneros literarios y, a su vez, que los sistemas literarios se tornen permeables a las influencias de múltiples tipos de discursos y referentes culturales.

Se trata en este sentido de literaturas de frontera que se relacionan con los cambios que tienen lugar en los sistemas epistemológicos y estructuras sociales, culturales y lingüísticas que suceden en donde se originan esas obras (Hernando, 2004). Sin embargo, el concepto de frontera aquí no se limita a su acepción territorial, pues se relaciona también con los márgenes que se establecen también en distintas áreas del saber, como formas de escindir el conocimiento, epistemologías, disciplinas y culturas, que estas literaturas buscan, intencionalmente, dislocar. Así, la frontera viene a ser metáfora de un espacio cultural y semiótico donde se generan discursos de la diferencia que "se encuentran de un lado del límite o borde, en el margen, ocupan un lugar de resistencia, politizados por la fuerza interna que los ha construido: la de representar las voces de los otros, el de materializar la experiencia desterritorializante, sea lingüística, geográfica o cultural” (Galván, 2002, p. 21).

La estructura de estos discursos constituye una forma especial, pues se trata de textos que desafían los cánones literarios: Verónica Galván (2002) lo identifica en el discurso testimonial, nosotros en aquel sector de la literatura indígena que se caracteriza por su condición transdiscursiva y enunciación heterogénea, y especialmente, en textos que responden a nuestra noción de heterogeneidad textual y que son de $c a$ rácter experimentaly excéntrico, tal como ocurre con el proyecto estético de José Luis Ayala y Cábala para inmigrantes, donde convergen fragmentos que corresponden a los géneros tradicionales (poesía, narrativa), al cruce de géneros diversos (narrativa y autobiografía), a otras artes y disciplinas (la pintura, el retrato, el dibujo y el collage), de textos aparentemente recogidos de la realidad o que imitan la estructura de textos informativos (recortes de diarios, cartas, avisos, informes, etc.), y de referentes culturales (lo andino y lo occidental). Poetas indígenas contemporáneos como Odi Gonzales, Fredy Roncalla y José Luis Ayala producen una escritura de carácter heterogéneo pues sus obras dialogan con dos tradiciones culturales: la 
estética occidental y la cultura andina. Se trata de una producción literaria en la que se "intersectan conflictivamente dos o más universos socioculturales" (Cornejo, 2011, p. 19), que se encuentran en un tensionante punto de inflexión, debido a que la confluencia de ambos sustratos no es necesariamente armónica y puede llevar, incluso, a una inestabilidad y confrontación epistemológica, tal como sucede en la narración autobiográfica del personaje principal de Cábala para inmigrantes, Rafael Olázabal, en que se evidencia un conflicto entre la racionalidad occidental y el pensamiento y la ontología andina.

En este sentido, proponemos que en este tipo de textos es posible observar la heterogeneidad en dos vertientes: una de carácter cultural, tal como lo ha planteado Antonio Cornejo Polar (2011), y otra de carácter textual —y no sólo literaria-, cuya particularidad es la experimentación con referentes estéticos y culturales y la superación de las fronteras de los géneros literarios y las artes.

Gran parte de este tipo de expresiones se vinculan con la vanguardia literaria de los años veinte, y en el contexto de la literatura peruana el referente fundamental será la vanguardia andina, conexión que nos permite conceptualizar estas literaturas en tanto estéticas neovanguardistas. Siguiendo a Hal Foster (2001) son neovanguardistas aquellas expresiones que en el campo artístico de la segunda mitad del siglo XX, plantean un retorno radical y una relaboración crítica de las técnicas, procedimientos y propósitos estéticos y políticos de la primera vanguardia, pero que en este periodo se centran en el cuestionamiento de la institucionalidad del arte, producto de su vinculación con los fenómenos políticos y los problemas propios de la época y lugar en que se desarrollan, así como por su afán por establecer una conexión entre el arte y la vida. ${ }^{5}$

En el repertorio literario indígena transdiscursivo y heterogéneo encontramos que la condición neovanguardista se plasma en tres aspectos fundamentales que atañen a la configuración de la obra literaria, a saber: en primer lugar, la primacía de la reflexión metatextual, la autorreflexividad y la metaficcionalidad como ejes articuladores del texto (aspectos que se relacionan con la heterogeneidad textual de los mismos productos estéticos), donde adquieren protagonismo el cuestionamiento de la noción de texto literario y de las formas escriturales; en segundo lugar, la experimentación con los géneros y tipos de discursos (también como forma de heterogeneidad textual); y, en tercer lugar, el discurso establece relaciones entre el arte, la vida y la política, enfatizando en la función del artista en la sociedad.

Vemos, en consecuencia, que existe una conexión necesaria entre las categorías teóricas de transdiscursividad, enunciación heterogénea, heterogeneidad cultural y

5 Oscar Galindo (2013) ha demostrado que algunos grupos hispanoamericanos cuyos proyectos estéticos responden a estas características son Diagonal Cero, Tucumán Arde, Nosferatu y Lagrimal Trifulca, en Argentina; Hora Zero y Kloaka en el Perú; El techo de la ballena y Tráfico en Venezuela; el Nadaísmo en Colombia; CADA y Tribu NO en Chile. 
textual, que se concretizan en un repertorio literario indígena cercano a lo que aquí hemos definido como neovanguardia, y paradigmático de ello es Cábala para inmigrantes.

\section{La escritura acéntrica de José Luis Ayala}

Aunque la necesidad de concretizar textualmente las vinculaciones entre la poesía $y$ las artes figurativas es de larga data, ${ }^{6}$ es claro que su punto culminante se produce en el contexto de la primera vanguardia.

El magnífico 5 metros de poemas (1927) de Carlos Oquendo de Amat propone como noción articuladora el "poema acéntrico", una forma de textualidad que releva su visualidad mediante la disposición de los significantes en la(s) página(s), con lo cual se formula una nueva posibilidad de leer un texto literario. Sabido es que "Film de los paisajes", "New York" y "Amberes" son poemas acéntricos. En la nota final del primero, Oquendo presenta una exquisita reflexión metatextual para definir esta nueva estética. Dice: "los poemas acéntricos vagan por los espacios subconscientes, o exteriorizadamente inconcretos son hoy captados por los poetas, aparatos análogos al rayo x, en el futuro, los registrarán”. La poesía acéntrica es, entonces, una estética del movimiento y del simultaneísmo lírico. Frente a un "poema céntrico", fijo en su estructura y lineal en su lectura, los "poemas acéntricos" son un desafío al lector. Su estructura corresponde a "poemas-dobles" (Areta Marigó, 2006) que, no obstante, tienen un título único, los versos se disponen a lo largo de dos o más columnas que ocupan la extensión de una o más carillas, de modo que los versos pueden leerse correlativamente o en forma separada, razón por la cual la compresión del texto requiere de actividad cooperativa del lector empírico.

Por su condición visual, es imposible no relacionar los poemas acéntricos con el cubismo y el simultaneísmo estético, técnica plástica para introducir contrastes y disrupciones en la representación: "el contraste simultáneo es el perfeccionamiento más novedoso del oficio, de esta técnica. El contraste simultáneo es profundidad vista-realidad-forma-construcción, representación. Se vive en la profundidad, se viaja por la profundidad" (Delaunay, 1912, p.76). La metarreflexión del pintor francés Robert Delaunay se concretizan en su serie abstracta "Les fenêtres", ${ }^{7}$ especialmente en "Les fenêtres simultanées sur la ville" (1912), que inspirará el poema "Fenêtres" (1912) de Guillaume Apollinaire, probablemente una de las primeras expresiones de simultaneísmo lírico, donde las imágenes que se proyectan desde la ventana se suceden mediante un sistema de contrastes cuya consecuencia es la fragmentación de la escritura.

6 Dos buenas revisiones del poema-objeto realizadas desde el ámbito hispanoamericano son las de Paz (1992) y Belli (2005).

7 "Las ventanas", realizadas entre 1912 y 1913. 
Los últimos versos del poema de Apollinaire que dicen: "se abre una ventana como una naranja/ el hermoso fruto de la luz", ${ }^{8}$ presentan una continuidad con la invitación al lector con que se inician los 5 metros de poemas: "abra el libro como quien pela una fruta”. En ambos textos la metaforización es un intento de hacer cosas con el lenguaje, materializarlo a través de la conjunción de elementos de distinto orden (la ventana-naranja; libro-fruta) y situarlos en un eje espacio-temporal que es, también, de carácter simultáneo: desde la ventana de Apollinaire se pueden ver "París Vancouver Hyères Maitenton New York y las Antillas", mientras que los poemas acéntricos de Oquendo se pasean por París, New York y Amberes.

No obstante, los textos de Ayala no están escritos en páginas-dobles, replican la intención que observamos en la escritura acéntrica y simultánea, y lo ejemplificaremos con los poemas "La realidad y el deseo", "Kunatakiraki" y "Final del camino".

"La realidad y el deseo"9 es un texto que solo en parte reproduce la estructura textual de un poema acéntrico - escritura en bloques pareados-, sin embargo, como consecuencia de la disposición de los significantes, las imágenes se presentan en contrapunto y simultaneidad. En este texto prima una reflexión metatextual sobre la escritura, la que se materializa en el dinamismo de los verbos que causan una sensación cinética: "Paso a paso la escritura/ avanza/ determina/ abrevia/ salta/ vence/ derriba/ derrumba/ acorta/ la distancia entre la imaginación y el deseo". Se trata, en definitiva, de la escritura como deseo, una máquina productora que despierta con estímulos de lo cotidiano: "una pregunta/ una palabra esdrújula/ un gesto", hasta con imágenes naif —en el sentido de art naif_, tales como "una mujer mirando al mar" o "un ave que cruza el cielo". Y desde allí surge la afirmación de que la "futura poesía/ emergerá del dominio del sortilegio/ la significación y la magia”, aspectos que se relacionan con el proyecto escritural de Ayala, donde la pregunta por la significación, por la sintaxis, la semántica y la semiótica de las palabras y las imágenes, en tanto signos expresivos, adquiere una relevancia fundamental y, por supuesto, es el motivo de los elementos oníricos y psicomágicos que aparecen en Cábala para inmigrantes.

"Kunatakiraki”, ${ }^{10} \mathrm{voz}$ aymara que significa '¿para qué?', introduce un cuestionamiento sobre la función de la escritura y del poeta en sociedad. En este poema donde la escritura acéntrica en bloques paralelos sirve como recurso para presentar gráficamente la enumeración caótica, el hablante lírico asume un posicionamiento ético frente lo que considera una amenaza a la condición humana: "La mohatra nos amenaza/ cuenta la horas/ agazapada/ escondida/ oculta/ en la sombra/ el silencio nos acosa”. De cierto modo, y quizás contrariamente a lo que planteaba el surrealis-

8 Los versos originales dicen: "La fenêtre s'ouvre comme une orange/ le beau fruit de la lumière" (Apollinaire, 143).

9 Ver Anexo 1.

10 Ver Anexo 2. 
mo vanguardista que no veía al inconsciente como algo intimidante sino un terreno a explorar, para el hablante los recovecos del inconsciente son un desafío. Así, lo acéntrico adquiere una nueva dimensión: el revisar y salirse de "los dogmas/ las doctrinas/ las reglas/ los credos", y ello implica la escritura pues el papel del escritor, desde esta perspectiva, es entregar las nuevas coordenadas para una sociedad equitativa, es decir, su deber es darle una nueva ética a la comunidad de la se siente parte. En otras palabras, vemos aquí el compromiso vanguardista de la vinculación entre el arte, la política y la vida.

Otra forma de poema acéntrico es "Final del camino", ${ }_{11}$ un texto manuscrito, cercano a lo caligramático, pues lo que podemos apreciar a primera vista como una enumeración caótica con forma de medialuna es igualmente un camino, señalizado por el rumbo de las flechas. Más allá de la temática —el encuentro con el otro amado-, su configuración textual es bastante significativa puesto que propone una estructura abierta que permite la participación del lector que, por medio de las señales de ruta que son las flechas y las indicaciones, puede movilizar su lectura y convertirse en el constructor del texto.

Estos tres poemas acéntricos son, en definitiva, una superación de la escritura y la lectura lineal — cartesiana, diría Ayala; céntrica probablemente desde la perspectiva de Oquendo-, donde el ejercicio poético constituye el núcleo de la arquitectura textual y que tiene como consecuencia el cuestionamiento de las formas escriturales y las hegemonías epistemológicas.

\section{Los nudos de la escritura: los quipullagemas y el poeta quipucamayoc}

Una de las formas de heterogeneidad textual más interesante que aparece en Cábala para inmigrantes es, probablemente, la réplica de la escritura de los pueblos andinos, los quipus. El procedimiento de José Luis Ayala consiste en una adaptación de la forma visual de un quipu como recurso gráfico para la escritura; de este modo, a partir de un componente cultural andino, se inscriben grafías en español, pero ello no implica el sometimiento, utilización o simplificación del sistema cultural andino, pues los temas que moviliza esta nueva forma textual están profundamente arraigados en la experiencia del mundo andino. En este sentido, podemos decir, que los quipullagemas son una escritura caligramática de carácter figurativo, cuya forma reproduce visualidad del quipu y este, a su vez, es el motivo de la reflexión poética.

Siguiendo la estructura de los antiguos quipus (Radicati di Primeglio, 2006), en los textos de Ayala los versos son la reproducción visual de las cuerdas, de modo que el primer verso (que también constituye el título del quipullagema) es la cuerda

11 Ver Anexo 3. 
principal, y de ella se desprenden versos-cuerdas colgantes y de ellas, a su vez, versos-cuerdas subsidiarias. ${ }^{12}$

La singular codificación de los quipus ha significado que se generen múltiples propuestas respecto de su simbología y distintas tesis interpretativas, sin embargo, tres son las más reconocidas, las cuales reducen a que:

1. los quipus tienen valor numérico, o sea sirven exclusivamente para expresar números; 2 . los quipus son instrumentos mnemotécnico de valor personal, es decir, sirven como auxiliar recordatorio para quien lo ha confeccionado o, a lo más, para unos cuantos que conocen el significado de los elementos que lo componen; 3. los quipus son verdadera escritura, o sea, sirven para expresar toda clase de ideas mediante signos convencionales (Radicati di Primeglio, 2006, p. 100)

La última interpretación, quizás la más provocativa e interesante, veremos, es la que suscribe Ayala en su propuesta estético literario. Esta tesis, sin embargo, no considera necesariamente la posibilidad de que en el mundo andino se haya alcanzado una escritura fonética, pues lo que se obtiene mediante nudos y colores son "innumerables significaciones de las cosas" (p. 130). Ello explica que una de sus posibles funciones haya sido la de consignar fechas, hechos históricos y localizaciones, a modo de escritura cronística (o quipu almanaque) o narrativa (Radicati di Primeglio, 1992; Urton, 2003).

En este sentido, los quipullagemas de Ayala, tanto por su estructuración como por la narratividad de sus versos, constituyen un complejo experimento textual, a través del cual se vehiculiza una literatura indígena con su raigambre cultural profunda. Un antecedente a la escritura en quipus de Cábala para inmigrantes aparece en uno de sus libros anteriores, Poesía para videntes (1988), donde se encuentra uno de los primeros "kipuemas", tal como allí primeramente denomina a este tipo de textos. A partir de la estructura del quipu, en este quipullagema podemos leer lo siguiente: ${ }^{13}$

12 En los quipus originales, se realizaban distintos tipos de nudos y dependiendo del lugar y nivel en donde estén situados, y de los colores y materiales con que estén hechos, variará en su simbolismo y significado.

Dos antecedentes importantes dicen relación con su antigüedad y uso, con variantes, a lo largo del continente, pues si bien tendemos a circunscribirlo a un tiempo y periodo específico (el periodo incaico), existe también información cronística, como la de Fray Antonio de la Calancha, que indica que "el uso de los quipus es inmemorial" y que su confección comenzó "desde que vino al mundo su dios Viracocha" (cit. por Radicati di Primeglio, p. 94). Además, diferentes culturas prehispánicas con distintos estadios de desarrollo, también recurrieron a su utilización como forma de comunicación: "el empleo simbólico de la cuerda en colores es muy extensivo en todo América y ejemplos son el "nepzualritzin" del Anahuac y las cuerdas empleadas por los zuñis durante las ceremonias del invierno” (p. 108). De igual forma, según el etnohistoriador José Bengoa (2002), la cultura mapuche, al sur del continente, también utilizaba un sistema mnemotécnico para recordar y transmitir mensajes, basado en cuerdas y nudos, llamado "prom".

13 Ver Anexo 4. 


\begin{tabular}{|l|l|}
\hline Cuerda principal & Un anónimo poeta andino ideó la escritura en hilos \\
\hline Cuerda colgante 1 & Todo podía ser posible en la continuidad de una poesía sin palabras \\
\hline Cuerda colgante 2 & Poesía casi secreta \\
\hline Cuerda subsidiaria 2.1 & Cifrada en colores y transmitida de generación en generación \\
\hline Cuerda colgante 3 & Había nudos \\
\hline Cuerda subsidiaria 3.1 & Pequeños que representaban otros kipuemas \\
\hline Cuerda colgante 4 & La poesía era cotidiana \\
\hline Cuerda colgante 5 & De modo que un verso podía tener el color del mar \\
\hline
\end{tabular}

Este texto evidencia características metarreflexivas, la intención que lo motiva es vincular esta nueva poética directamente con la cultura andina y con el quipu como forma escritural, como un sistema de transmisión del conocimiento intracultural que remite a la matriz cultural con la cual se identifica el sujeto escritural. A través de los quipullagemas, Ayala alude a la condición cotidiana de las manifestaciones culturales andinas, tales como los cantos y los quipus, pues el conocimiento oral pasa de generación en generación, como el quipu "pasa de mano en mano". Se trata de la memoria colectiva que reactivan los quipullagemas, estableciendo así tramas con la tradición (Espino, 2010).

Otra forma de vinculación con la cultura andina se presenta mediante la equiparación entre el sujeto textual y el quipucamayoc, ${ }^{14}$ en tanto que sus roles se homologan en esta poesía "casi secreta" y "cifrada en colores", pues el sujeto de la enunciación es el heredero de ese "anónimo poeta" que "ideó la escritura en hilos" y, por lo tanto, continuador de una tradición cultural. El uso cotidiano al que alude el texto, dice de la relación que el empleo de los quipus "estaba muy difundido y lo aprovechaba el hombre común para su uso personal, como lo demuestra el hecho de que nuestro instrumento ha subsistido precisamente bajo este aspecto entre los pastores de la sierra peruana" (Radicati di Primeglio, pp. 134-136). Este poeta quiere hacer del quipu una fuente escritural y restituir su uso cotidiano por medio de la palabra poética, para así resituarlo en un nuevo contexto, haciendo dialogar dos nociones muy distintas de escritura, dos epistemes diferentes, por eso este poeta quipucamayoc, hacedor de kipuemas, es un sujeto transdiscursivo y heterogéneo que, a pesar de su condición bicultural, asume y escoge su herencia indígena, la escritura de sus ancestros, convirtiéndola en memoria reactivada.

Ya asumida esta condición textual, el poeta quipucamayoc de Cábala para inmigrantes, en cambio, busca plasmar la experiencia de la migración y la cercanía de la muerte como móvil de la escritura. En este sentido, los textos que responden a estas características temáticas y textales son "Otra vez ha regresado la muerte..." (Collage $n^{\circ}$ 227), "Reconozco sobre la nieve los pasos de la muerte..." (Collage $\left.n^{\circ} 169\right)$ y "Llegará la muerte una tarde en que haya escrito un poema para ti..."

14 La noción de quipucamayoc alude tanto a los archivos de quipus que, en su tiempo, constituían verdaderas bibliotecas, como a las personas cuyo "oficio exclusivo era valerse de los nudos para fines típicamente burocráticos" (Radicati di Primeglio, p. 134), función transmitida de generación en generación. 
(Collage $\mathrm{n}^{\circ} 127$ ), pero debido a su representatividad, solamente analizaremos el primer texto, ya que en su estructura y tratamiento temático es particularmente significativo de nuestro planteamiento. El texto dice lo siguiente: ${ }^{15}$

\begin{tabular}{|l|l|}
\hline Cuerda principal & $\begin{array}{l}\text { Otra vez ha llegado la muerte y la he visto en el jardín cuando } \\
\text { escribía para ti }\end{array}$ \\
\hline Cuerda colgante 1 & Será un viernes que regrese de la muerte \\
\hline Cuerda colgante 2 & me abrazará y juntos navegaremos río arriba \\
\hline Cuerda colgante 3 & hasta tramontar la extensión de la Laguna de la Muerte \\
\hline Cuerda colgante 4 & cuando termine el tiempo y empiece el ciclo sin retorno \\
\hline Cuerda colgante 5 & tendré listo mi equipaje y mi consciencia estará tranquila \\
\hline Cuerda colgante 6 & Nada debo ni me deben, perdono las ofensas que me hicieron \\
\hline Cuerda colgante 7 & Perdono a quien me amenazó con ultrajarme si publicaba una cronivela \\
\hline Cuerda colgante 8 & perdono a quienes me persiguieron implacablemente como un animal \\
\hline Cuerda colgante 9 & perdono a quien confié mi habitación en París y robó mis enseres \\
\hline Cuerda subsid. 9.1 & He lavado mi corazón con la lluvia que cae en Jacha Xa a la humanidad \\
\hline Cuerda colgante 10 & y no me causa temor si la muerte llegara una tarde \\
\hline Cuerda colgante 11 & que esté escribiendo un libro de quipullagemas \\
\hline Cuerda colgante 12 & Si hay algo que me duele mucho más \\
\hline Cuerda colgante 13 & es no haber podido hallar el anillo que perdí en Fontaine Blue \\
\hline Cuerda colgante 14 & Eso es todo, no me arrepiento de haber dicho \\
\hline Cuerda colgante 15 & que tarde o temprano acabará el reino de odio a la humanidad \\
\hline Cuerda colgante 16 & Me he convencido de que la civilización es una inmensa cárcel \\
\hline Cuerda colgante 17 & de las que solo nos libera la muerte que es otra forma de vida \\
\hline
\end{tabular}

En este texto, donde surge la denominación textual quipullagema, como forma escritural que vincula lo occidental con lo andino, la enunciación recuerda un testamento, una escritura para posteridad donde el sujeto textual da cuenta de una especial manera de enfrentar la muerte, no como fin de la existencia si no como trascendencia. Más allá de la impronta autorreferencial y testimonial que marca parte del quipullagema, en este se pueden apreciar ciertas claves culturales que dan cuenta de la profunda integración del mundo andino.

En primer lugar, la muerte se anuncia aquí como presagio de la inminente partida. La muerte personificada persigue constantemente al sujeto lírico; así, la cuerda principal se inicia diciendo: "otra vez ha llegado la muerte" indica su presencia la recurrente en la cotidianidad, y haberla "visto en el jardín cuando escribía para ti”, pues en la cultura andina la muerte siempre se anuncia. En este sentido, según Lumperio Mamani (2001), para la cultura aymara la concepción de la muerte y del mundo es "diferente de la visión de Occidente, por cuanto todo lo que existe en el mundo tiene vida, y todos sus elementos tienen la virtud de relacionare y, además, transcurren por sus respectivos ciclos vitales", aspecto que se replica en la visión de la muerte, pues, "se percibe como una forma de vida, que ocurre después del fallecimiento. Para ello es necesario morir (o "permanecer dormido"). Existe la creencia

15 Ver Anexo 5. 
de que en esta nueva condición la vida se desarrolla con las mismas peculiaridades en que este mundo" (Mamani, 2001, p. 236). Esto explicaría por qué la muerte puede aparecer personificada en este texto como un ser fulminante y por qué su presencia constituye un augurio, debido a que "en el mundo aymara, los fallecimientos son posibles de percibirlos antes de que ocurran" (2001, p. 237) y está se puede manifestar de diferentes formas, sobre todo, en los sueños.

En la cultura andina la muerte es un rito, un sistema, tanto así que la ruta que lleva a la trascendencia hacia el Alax Pacha se prepara mediante un complejo sistema simbólico, dentro de la cual los presagios son sólo una parte constitutiva de él, pero que continúa con el velorio, el entierro, el despacho del muerto (o alma despacho, según Robin, 2005) y la celebración de Todos los Santos. En tanto nueva forma de vida, con la muerte el alma transita, viaja, de modo que "los difuntos se convierten en migrantes al otro mundo", motivo por el cual la ritualidad considera que "al momento de emprender su viaje les dan de comer, les dan de beber, les dan vestido, les dan una parcela, le hacen participar de sus fiestas, es decir, les dan lo necesario para que se realicen en esta como en la otra vida" (Acosta Veizaga, 2001, p. 70).

El quipullagema de Ayala, en este sentido, no se encuentra alejado de estas coordenadas culturales sobre la muerte, las primeras cuerdas expresan con claridad este posicionamiento: "Será un viernes que regrese de la muerte/ me abrazará y juntos navegaremos río arriba/ hasta tramontar la Laguna de la Muerte/ cuando termine el tiempo y empiece el ciclo sin retorno/ tendré listo mi equipaje y mi alma estará tranquila”. El alma viajera debe transitar hacia nuevas fronteras provista de un equipaje simbólico que ayudará a alcanzar su destino. La alusión al agua, al río como lugar de paso, constituye un referente simbólico en tanto que el agua es el símbolo del flujo cósmico en los Andes, pues "además de ser fuente de vida, es un camino para trasladarse y puerta de escape” (Lozada, 2006, p. 101), por lo tanto, no es de extrañar que las almas de los difuntos deban volver al origen de la vida para comenzar una nueva. Asimismo, el antropólogo Gerardo Fernández Juárez refiere, en relación con los ciclos de la vida, que: "tras la muerte, efectuada la ceremonia de los ocho días, el difunto emprende un agotador camino por sendas espinosas debiendo atravesar una gran masa de agua (lago, río Jordán) ayudado por un perro negro" (1995, p. 76), que lo ayudará a sortear los peligros del viaje.

En este contexto, la limpieza del cuerpo, el lavatorio de sus pertenencias, permite que quienes están cerca no se contaminen con la muerte, sin embargo, en el quipullagema de Ayala es el sujeto lírico quien realiza el ritual de limpieza de su propio cuerpo y de su alma, liberándose, mediante la escritura, de las cargas que ha debido llevar en su vida: "He lavado mi corazón con la lluvia que cae en Jacha Xa a la humanidad/ y no me causa temor si la muerte llegara una tarde/ que esté escribiendo un libro de quipullagemas". La muerte, de este modo, es esperada y resulta ser uno de los aspectos fundamentales mediante los cuales el hablante, un migrante andino en París, se vincula con la cultura y cosmovisión de sus raíces. 
Los nudos de la escritura de los quipullagemas y de este poeta quipucamayoc son, en definitiva, la escritura poética como forma de recuperación de los elementos constitutivos de su cultura y la escritura autorreferencial como forma de mediación entre los referentes culturales externos adquiridos mediante la migración y la cultura andina, base sustancial de la subjetividad de un quipucamayoc en tránsito, que se mueve entre fronteras culturales y cosmovisionales, y fronteras entre distintos tipos de mundo (el mundo de la vida y el mundo de la muerte), pero que interpreta su experiencia con ojos andinos.

\section{Conclusiones}

El análisis de la propuesta estética de José Luis Ayala, especialmente los poemas acéntricos y los quipullagemas son una de las posibles formas en que se presenta la heterogeneidad textual y la neovanguardia en una obra especialmente dinámica y compleja.

En primer lugar, Cábala para inmigrantes forma parte de un repertorio textual surgido en el contexto de la literatura indígena contemporánea que se caracteriza porque sus autores responden a una condición transdicursiva (Rodríguez, 2013), lo que les permite tender puentes entre la cultura indígena y la occidental, pues se encuentran en una realidad intercultural; no obstante, en su mediación cultural estos escritores han debido dar cuenta del complejo choque epistemológico que significa el estar sumergidos entre dos universos culturales. Estas obras constituyen enunciaciones heterogéneas (Rodríguez, 2009) porque tienden a optar por una de las dos heredades, mostrando con la escritura, los conflictos que actualmente enfrentan las culturas indígenas y los sujetos mestizos.

En segundo lugar, obras como ésta se caracteriza por su compleja estructura textual, lo que da cuenta de la voluntad experimental que mueve estos proyectos estéticos. En este sentido, hemos identificado la heterogeneidad textual como la confluencia en el texto de diversas formas de expresión, géneros literarios y tipos de discurso, cuyo objetivo puede ser tanto generar una profunda interrelación entre el argumento, motivo o tema de la obra y la manera en que ésta se expresa, como también constituir por sí mismo un modo de reflexionar sobre la función del texto literario, de los géneros y del sistema de representación en la literatura, tratando, asimismo, de superar los cánones estéticos y proponer una refundación estética basada en nuevos paradigmas.

Esta última característica nos hace pensar que en estas obras existe una vinculación con el espíritu que animó las vanguardias literarias de la primera mitad del siglo veinte en Hispanoamérica y, en el caso peruano, creemos que ello se debe, principalmente, al modelo que para la literatura indígena contemporánea ha significado la vanguardia andina en Puno (en las figuras de Gamaliel Churata y el grupo Orkopata y, por supuesto, también Carlos Oquendo de Amat), principalmente en 
la original manera en que los autores pertenecientes a la generación surgida en los años veinte han vehiculizado la relación entre la obra literaria y el sustrato cultural andino. Así, creemos que la renovación de la vanguardia, que nosotros identificamos como neovanguardista, se presenta mediante tres aspectos que se relacionan, por cierto, con la heterogeneidad textual. El primero expresa la relación con que la metarreflexión constituye un eje escritural, a través del cual la intención es el cuestionamiento de los modos de hacer literatura; en segundo lugar, se aprecia una voluntad experimental que apunta a desafiar la estructura y configuración del texto literario; y, en tercer lugar, estas obras expresan una particular manera de vincular el arte con la vida y la política. Por ello en textos como Cábala para inmigrantes, podemos observar que en la obra existe una estrecha relación entre el sujeto escritural y el sujeto autor, de tal modo que aspectos de la biografía atraviesan la escritura, lo que se comprueba cuando vemos que el texto incluye "documentos de la realidad" (recortes de periódico, por ejemplo), que tiende a darle un soporte a la historia del protagonista. La vinculación política, en tanto, se plasma en la crítica que el migrante andino realiza de la razón occidental y la cultura que lo rechaza por su diferencia.

Podemos identificar estas características en el corpus textual que hemos seleccionado, pues tanto los poemas acéntricos como los quipullagemas dan cuenta de que la obra de Ayala es de carácter neovanguardista y textualmente heterogénea. En primer lugar, hemos analizado los poemas acéntricos de Ayala en relación a la estructura y finalidad que tenían los textos de Carlos Oquendo de Amat, y ello nos ha permitido proponer que existe una concordancia entre esta forma textual y el simultaneísmo lírico de la poesía de cuño cubista. Así, hemos podido ver que al igual que en la poesía de Oquendo de Amat, en los textos de Ayala lo acéntrico tiene como objetivo dotar a la poesía de movimiento y de carácter cinético para que las imágenes que se proyectan en la lírica se presenten mediante el contrapunto y la simultaneidad. En los textos de Ayala lo acéntrico permite la actividad cooperativa del lector empírico que puede moverse por el texto construyendo nuevos sentidos en la lectura; por este motivo, entendemos que este tipo de textos permite una revisión y superación de las formas escriturales céntricas y lineales.

En segundo lugar, hemos querido dar cuenta de los quipullagemas como una forma de heterogenidad textual a través de la cual se moviliza la escritura occidental y el pensamiento andino. Los quipullagemas de Ayala cumplen con los objetivos que hemos identificado para la heterogeneidad textual: al ser una escritura caligramática que replica la estructura y visualidad del quipu andino, éste mismo complementa el tema de la obra, es decir, la conjugación de epistemes culturales distintos en la psiquis de un sujeto que busca rescatar los elementos fundamentales de su cultura; a la par de lo anterior, vemos que se reflexiona metapoéticamente sobre esta forma escritural única, y por ello podemos identificar al sujeto escritural con la figura de los antiguos quipucamayoc, en tanto que su objetivo es restituir la cultura andina mediante la palabra poética y, especialmente, por medio del quipu como elemento 
cultural privilegiado. Con los quipullagemas es que la escritura heterogénea de José Luis Ayala establece vínculos con el universo cultural andino, donde están los nudos de la escritura.

\section{Referencias}

Acosta Veizaga, Orlando. (2001). "La muerte en el contexto Uru: el caso Chipaya". Revista Chungará 33, $\mathrm{N}^{\circ} 2$ pp. 259-270.

Apollinaire, Guillaume. (S/f). "Les fenêtres”. Ed. y trad. Roger Shattuck. Selected Writtings. New York: New Direction Books: 40-42.

Areta Marigó, Gema. (2006). "La poesía acéntrica de Carlos Oquendo de Amat". Poesía Hispanoamericana. Imagen, Ed. Mariluci Guberman. Río de Janeiro: Universidad Federal de Río de Janeiro, pp. 69-80. https://goo.g1/Xhhg2w

Ayala, José Luis. 1988. Poesía para videntes. Lima: Editorial Juan Mejía Baca.

- (2003). Cábala para inmigrantes. (Antilaveno/ Poemallages). Lima: Noceda Editores SAC.

Belli, Carlos Germán. (2005). “Oquendo de Amat panvanguardista”. Dedocrítico, Revista de literatura 11, XI, pp. 47-68.

Bengoa, José. (2002). Historia del pueblo mapuche (siglo XIX - XX). Santiago: LOM.

Bueno Chávez, Raúl. (2004). Antonio Cornejo Polar y los avatares de la cultura latinoamericana. Lima: Universidad Nacional Mayor de San Marcos, Fondo editorial, 2004. https://goo.g1/36xnch

Cornejo Polar, Antonio. (2011). Escribir en el Aire. Ensayo sobre la heterogeneidad socio-cultural en las literaturas andinas. Lima/Berkeley: Latinoamericana Ediciones- CEP.

Delaunay, Robert. (S/f). “Notas sobre el simultaneísmo (1913)”. Ed. Ángel González García, Francisco Calvo Serraller y Simón Marchán Fiz. Escritos de arte de vanguardia 1900/1945. $3^{\circ}$ ed. Madrid: Ediciones Akal, pp. 75-76.

Espezúa Salmón, Dorian. (2007). "Vanguardismo andino en el Boletín Titikaka (1926-1930)". CELEHIS, Revista del Centro de Letras Hispanoamericanas 18, 16, pp. 219-245.

Espino, Gonzalo. (2010). Literatura oral o literatura de tradición oral. Lima: Pakarina Ediciones.

Fernández Juárez, Gerardo. (1995). El banquete aymara. Mesas y yatiris. La Paz: Hisbol.

Foster, Hal. (2001). El retorno de lo real. La vanguardia a fines de siglo. Madrid: Akal.

Galindo, Oscar. (2013). "Neovanguardias hipervitalistas en la poesía hispanoamericana (1958-1976): nihilistas, revolucionarios, solidarios y amorosos”. Taller de letras 52, pp. 11-37.

Galván, Verónica. (2002). "Discursos fronterizos". Diálogos Latinoamericanos 6, pp. 21-31.

Hernando, Ana María. (2004). "El tercer espacio: cruce de culturas en la literatura de frontera”. Revista de Literaturas Modernas 34, pp. 109-120. 
Lienhard, Martín. (1992). La voz y su buella. Escritura y conflicto cultural en América Latina 1492-1988. Lima: Editorial Horizonte.

Lozada, Blitz. (2006). Cosmovisión, historia y politica en los Andes. La Paz: Producciones CIMA.

Mamani, Luperio David Onofre. (2001). "Alma Imaña. Rituales mortuorios andinos en las zonas rurales aymara de Puno circunlacustre (Perú)”. Revista Chungará $33, \mathrm{~N}^{\circ} 2$, pp. 235-244.

Mamani, Mauro. (2009). Poéticas andinas. Puno. Lima/ Barcelona: Pájaro de fuego Editores- Instituto de Investigaciones Humanísticas, Facultad de Letras y Ciencias Humanas, Universidad Mayor de San Marcos - Guaraguao, Revista de Cultura Latinoamericana (CECAL).

Mendoza Borda, Gloria. (2005). “El grupo oquendiano de Puno”. Dedocrítico, Revista de literatura 11, XI, pp. 135-145.

Morales, Leonidas. (2001). La escritura de al lado. Géneros referenciales. Santiago de Chile: Cuarto Propio.

Murra, John. (1975). Formaciones económicas y politicas del mundo andino. Lima: Instituto de Estudios Peruanos ediciones.

Noriega Bernuy, Julio. (2012). Caminan los apus. Escritura andina en migración. Lima: Pakarina Ediciones.

Oquendo de Amat, Carlos. (2005). 5 metros de poemas. Lima: Editorial Universitaria de la Universidad Ricardo Palma. (Edición facsimilar).

Paz, Octavio. (1992). "Poemas mudos y objetos parlantes (André Bretón)”. Vuelta 182 pp. 12-14. http://www.letraslibres.com/pdfmex/98691

Radicati di Primeglio, Carlos. (2006). Estudios sobre los quipus. Lima: UNMSM, Fondo Editorial; COFIDE; Instituto Italiano di Cultura.

Rodríguez Monarca, Claudia. (2009). “Enunciaciones heterogéneas en la poesía indígena actual de Chile y Perú”. Estudios Filológicos 44, pp. 181-194.

_ (2013). "Los espacios de la poesía indígena: agenciamientos y metatextos". Taller de letras 52, pp. 157-174.

Robin, Valérie. (2005). "Caminos a la otra vida. Ritos funerarios en los Andes peruanos meridionales". Molinié, Antoinette (comp.). Etnografías del Cuzco. Cuzco/Nanterre: Estudios Regionales Andinos Bartolomé de Las Casas / Instituto Francés de Estudios Andinos / Laboratoire d'ethnologie et de sociologie comparative.

Solomon, Frank. (2004). The coord keepers: khipus and cultural life in a Peruvian Village. Durham: Duke University.

Urton, Gary. (2003). Signs of the Inka Khipu. Binary coding in the Andean Knotted-Strings records. Austin: University of Texas Press. 


\title{
ANEXOS
}

Anexo 1: "La realidad y el deseo"

\section{LA REALIDAD Y EL DESEO}

Paso a paso la escritura

\author{
avanza \\ determina \\ abrevia \\ salta \\ vence \\ derriba \\ derrumba \\ acorta \\ la distancia entre la imaginación y el deseo. \\ Deja impresas sus huellas
}

sobre la fresca arcilla de la intemporalidad.

Es una pregunta
un gesto
un libro abierto en la mañana
un ave que cruza el cielo
un amor inexistente

Aveces
Entonces es posible
renacer remontar retomar revertir regresar
hasta la primera oración escrita en lienzos del espacio.
Por tanto:
una palabra esdrújula una mujer mirando al mar un poema aún no escrito la voz de un niño un inesperado adiós

$$
\begin{gathered}
\text { Afirmar que la futura poesía } \\
\text { emergerá del dominio del sortilegio, } \\
\text { la significación y la magia. }
\end{gathered}
$$




\section{Anexo 2: "Kunatakiraki"}

\section{KUNATAKIRAKI ( $\left.{ }^{*}\right)$}

\begin{tabular}{|c|c|c|}
\hline La mohatra & nos amenaza & \\
\hline & cuenta las horas & \\
\hline & agazapada & \\
\hline & $\begin{array}{l}\text { escondida } \\
\text { oculta }\end{array}$ & \\
\hline & en la sombra & \\
\hline el silencio & nos acosa & \\
\hline en el último instante & espera & está en \\
\hline & donde & la subconciencia \\
\hline & $\begin{array}{l}\text { confluyen } \\
\text { Jos caminos }\end{array}$ & la extraconciencia \\
\hline & las rutas & la anticonciencia \\
\hline & y final & la paraconciencia \\
\hline & de las edades & $\begin{array}{l}\text { la metaconciencia } \\
\text { por eso habrá }\end{array}$ \\
\hline & & entonces que \\
\hline Al fin & $\begin{array}{l}\text { escribir } \\
\text { todas las }\end{array}$ & novelas \\
\hline blarán & luchar & una \\
\hline todos los & redimir & por \\
\hline
\end{tabular}

antinovelistas. los verbos.

En nombre de la humanidad

$\begin{array}{ll}\text { ellos revisarán } & \\ \text { los dogmas } & \text { las doctrinas } \\ \text { las reglas } & \text { los credos } \\ \text { los métodos } & \text { los decretos leyes } \\ \text { los procedimientos } & \text { los tratados } \\ \text { los reglamentos } & \text { los convenios } \\ \text { las leyes } & \text { los pactos } \\ \text { las ordenanzas } & \text { e instaurarán la equidad. }\end{array}$

Quedarán nulos

los acuerdos

estatutos

códigos

reglamentos y códices que lesionen la condición humana.

$\left({ }^{*}\right)$ ¿Para qué?, En idioma aimara. 


\title{
Anexo 3: "Final del camino"
}

$$
\text { un tulgot }
$$

un postó - una pabolera

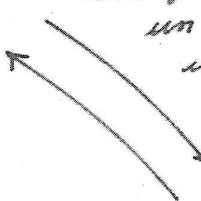

un restascio

wh muto

we Lema

ure axtoyo

una yolonghiona.

(6) atomentado (a)

(*) frime (a)

(*) imisible

(*) silenciaso (a)

(x) extraño (a)

Pe timal del aminotay

$(*)$ permenente

(x) cullodo (a)

(*) ouctsto (a)

(स) umpaloable

(*) iettema (o) una stancia

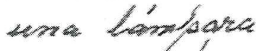

une soma

une derma

un desiento

un nesplomdes

s

ans paringe

un menal

una ciónaga

une ventama

un riño

une lloxe

urra fovada

b

e

á

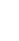

en are

una forlosa

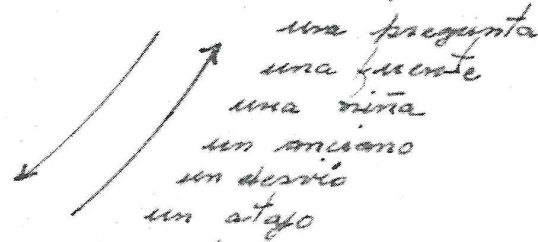

urne trompesa

wem foema

whe forware

Cone más nellá

แx 40425

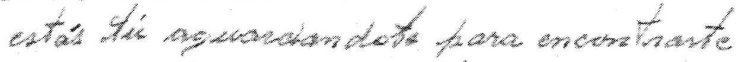

sontigo mismo.

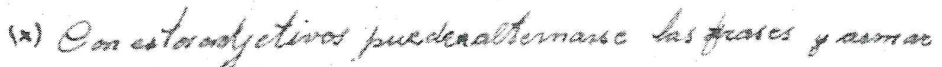
maxios textos. 
Anexo 4: "Un anónimo poeta andino ideó la escritura en hilos"

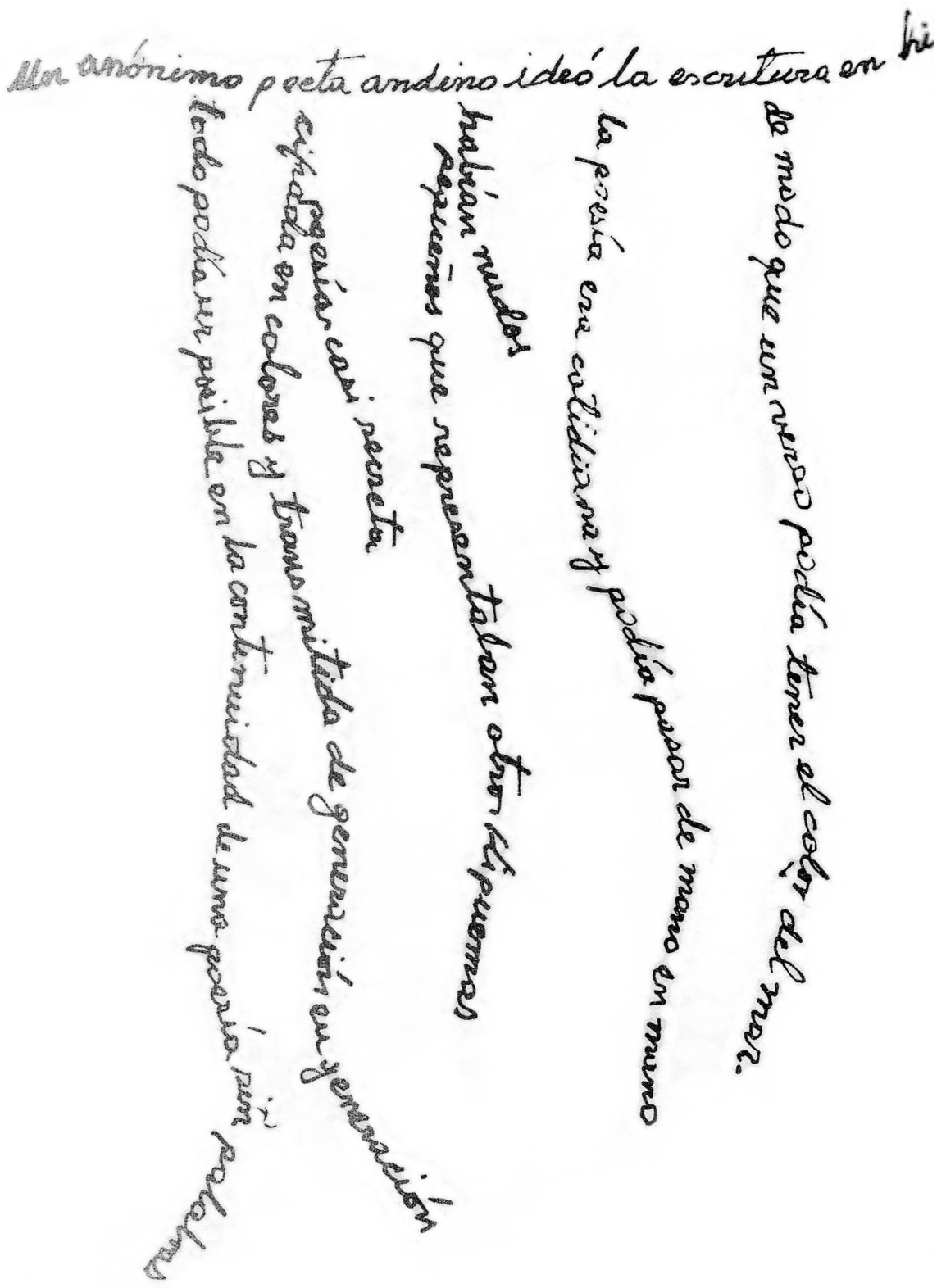




\section{Anexo 5: “Otra vez ha llegado la muerte..."}

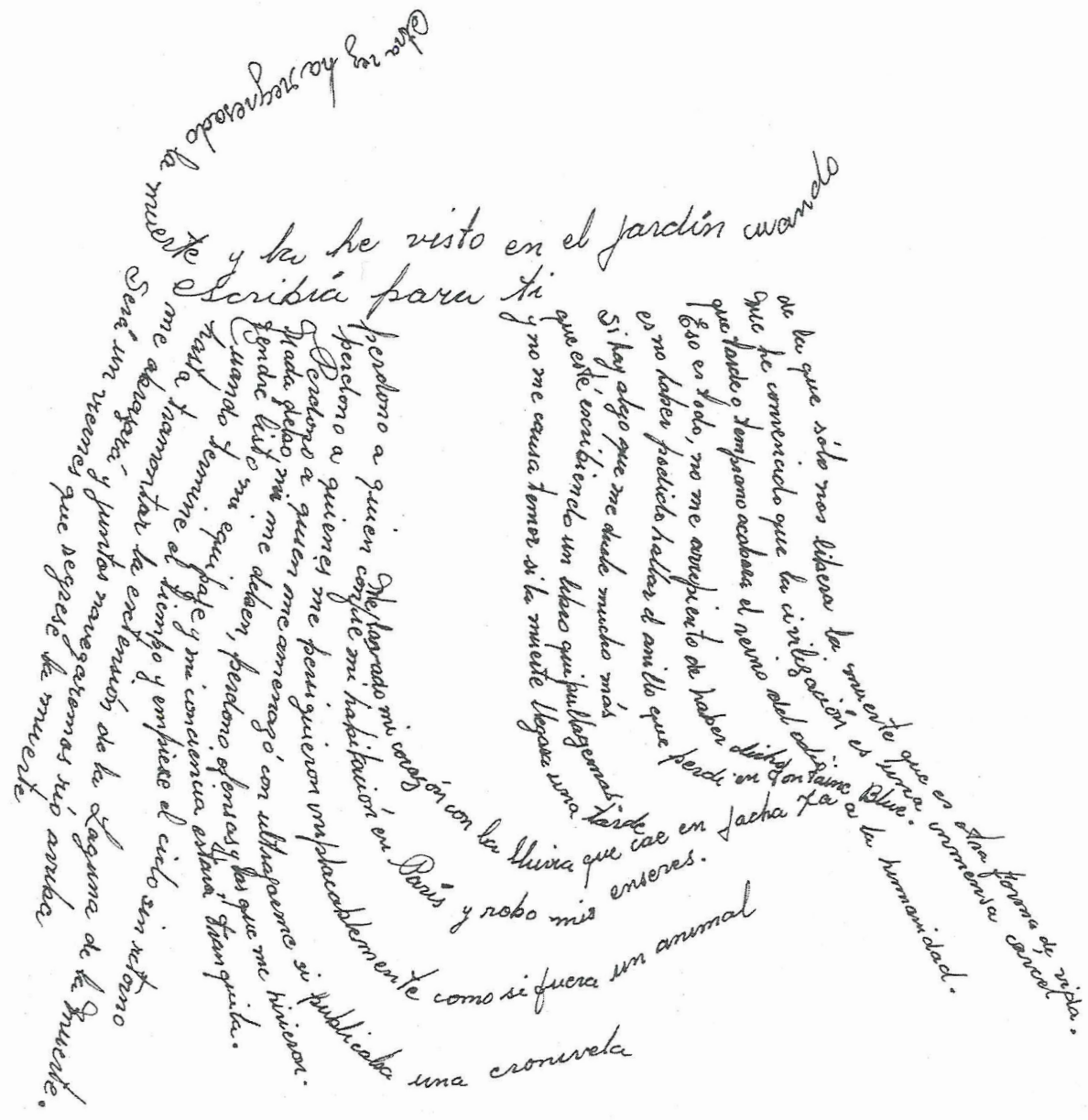


